\title{
Multi-machine transient stability by using static synchronous series compensator
}

\author{
Nur Ashida Salim ${ }^{1}$, Nur Diyana Shahirah Mohd Zain², Hasmaini Mohamad³, \\ Zuhaila Mat Yasin ${ }^{4}$, Nur Fadilah Ab Aziz ${ }^{5}$ \\ ${ }^{1,2,3,4}$ Faculty of Electrical Engineering, Universiti Teknologi MARA (UiTM), Selangor \\ ${ }^{5}$ Department of Electrical Power Engineering, Universiti Tenaga Nasional, Malaysia
}

\section{Article Info}

Article history:

Received Dec 14, 2019

Revised Feb 12, 2020

Accepted Mar 3, 2020

\section{Keywords:}

Controller

FACTS device

Power system stability

Static synchronous series

compensator

Transient stability

\begin{abstract}
Transient stability in power system is vital to be addressed due to large disturbances that could damage the system such as load changes and voltage increases. This paper presents a multi-machine transient stability using the Static Synchronous Series Compensator (SSSC). SSSC is a device that is connected in series with the power transmission line and produces controllable voltage which contribute to a better performance in the power system stability. As a result, this research has observed a comparison of the synchronization of a three-phase system during single-phase faults before and after installing the SSSC device. In addition, this research investigates the ability of three different types of controllers i.e. Proportional Integral (PI), Proportional Integral Derivation (PID), and Generic controllers to be added to the SSSC improve the transient stability as it cannot operate by itself. This is because the improvement is too small and not able to achieve the desired output. The task presented is to improve the synchronization of the system and time taken for the voltage to stabilize due to the fault. The simulation result shows that the SSSC with an additional controller can improve the stability of a multi-machine power system in a single phase fault.
\end{abstract}

This is an open access article under the CC BY-SA license.

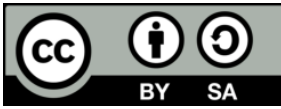

\section{Corresponding Author:}

Nur Diyana Shahirah Mohd Zain, Faculty of Electrical Engineering, Universiti Teknologi MARA (UiTM), 40450 Shah Alam, Selangor Email: dieyanaz12@gmail.com

\section{INTRODUCTION}

Power system operation is the process of transmitting electrical energy based on required demand. Stability in a power system is the ability of the system to return to normal condition [1-3] which is the steady state condition within a minimum possible time after a transient fault or disturbance and it is dependent on the behaviour of the synchronous machines after a disturbance. Therefore, stability in a power system is one of the main problems in the power system operation [4] due to the huge demand for which there is a need to add the installation [5], connection, or generation of a large unit of voltage etc. When the system is unstable, a three-phase system will oscillate asynchronously between each other and affect the system. Stability disturbances are caused by load changing, short circuit between line and ground, line to line fault, threephase fault, switching, etc [6]. Normally, the three-phase fault is the most common fault to occur as it causes maximum acceleration of the connected machines. 
Transient stability is taken into consideration in this paper since it has the ability to maintain and synchronise the acceleration of a machine when it is subjected to transient disturbance. The transient stability of a multi-machine system [7] can be maintained and improved by installing a Flexible AC Transmission Systems (FACTS) device [8,9]. FACTS is a device that is effective in controlling power flow, damping power system oscillations and improving the controllability and transfer capability of a power network. FACTS can also control the parameters and variables of a transmission line such as line impedance, terminal voltage, and voltage angle in effective ways since it is being increasingly used in power systems currently [10]. There are many FACTS devices available. SSSC (Static Synchronous Series Compensator) is a series FACTS device and one of the components that is proposed in this paper as a way to improve multi-machine transient stability [11]. An SSSC device will generate AC voltage and when connected in series to a power transmission line, it is able to control three parameters simultaneously such as line impedance, voltage, and phase angle. This paper only focuses on the effect of voltage if the disturbance occurs and the difference between three types of SSSC controllers which are PI, PID, and Generic controllers [12].

A simulation of stability in a power system has been carried out by using MATLAB Simulink [13]. Simulink is a software package that enables us to model, simulate, and analyse systems whose outputs change over time [14]. A Simulink system is configured in terms of a block diagram which is easy to build as it provides a drag-drop method to build a model in block diagram and the simulation results are displayed perfectly [8]. In this paper, a Simulink model is developed to improve the multi-machine system by using an SSSC device as it is widely used for research work and in the field of power systems [9].

\section{CONCEPT OF STATIC SYNCHRONOUS SERIES COMPENSATOR}

In order to test a power system's stability, a two-machine system is connected with a Static Synchronous Series Compensator (SSSC). The SSSC consists of a voltage source converter and coupling transformer that will connect to a transmission line in series [15], [16]. The SSSC is used to control the active and reactive power in the transmission line. Based on Figure 1, the transmission line is connected to an AC system and the other side is a capacitor and battery. The battery is assumed as a DC source to allow active power as well as reactive power exchanges with the AC system. The exchanges of real and reactive power can be determined from voltage, $\mathrm{Vq}$ with respect to the transmission line [17]. In Figure 1, Vdc and Vout are the DC voltage source and output voltage of the converter, respectively, Iline is the line current while Iac and Idc are the AC current and DC current, respectively.

Because of the operating characteristic, it has the ability to control the steady state performance and play a more important role in reactive power and voltage [18]. In SSSC, when VSC is connected in series with the coupling transformer, it will produce controllable voltage $(\mathrm{Vq})$ in quadrature with the line current to perform the function as a variable reactance compensator, either in capacitive or inductive mode. Meanwhile, VSC uses a forced commutated power electronic device to produce an AC voltage from a DC voltage source $[12,16,18,19]$. SSSC uses additional controllers such as Proportional Integral (PI), Proportional Integral Derivative (PID), and Generic controllers to modulate the injected voltage of $\mathrm{Vq}$ [20].

$$
\mathrm{Vq}=\Delta \mathrm{Vq}+\text { Vqref }
$$

- $\quad$ PI controller: proportional gain $(\mathrm{Kps})$ and integral gain $(\mathrm{Ki} / \mathrm{s})$

- $\quad$ PID controller: proportional gain $(\mathrm{Kpd})$, integral gain $(\mathrm{Ki} / \mathrm{s})$ and derivative gain $(\mathrm{Kds})$

- $\quad$ Generic controller: gain (Ks) and time constants (T1,T2,T3,T4)

Block diagram of PI, PID and Generic controllers as in Figure 2 to Figure 4 [21].

In Figure 2 to Figure 4, Vqref represents the reference injected voltage as desired by the steady state power flow control loop. The steady state power flow loop acts quite slowly, hence by injecting the Vqref it will be constant during the disturbance period [22]. The output of the block diagram will be supplied to the SSSC and the desired value of Vqref is recorded to differentiate the stability time of the three types of controllers. 


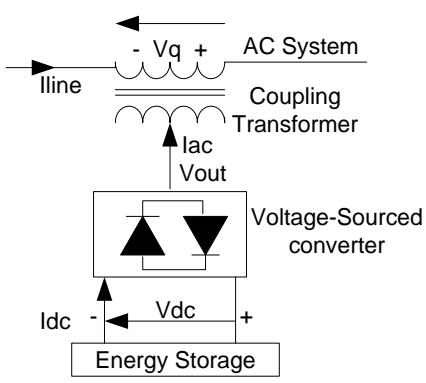

Figure 1. Static synchronous series compensator

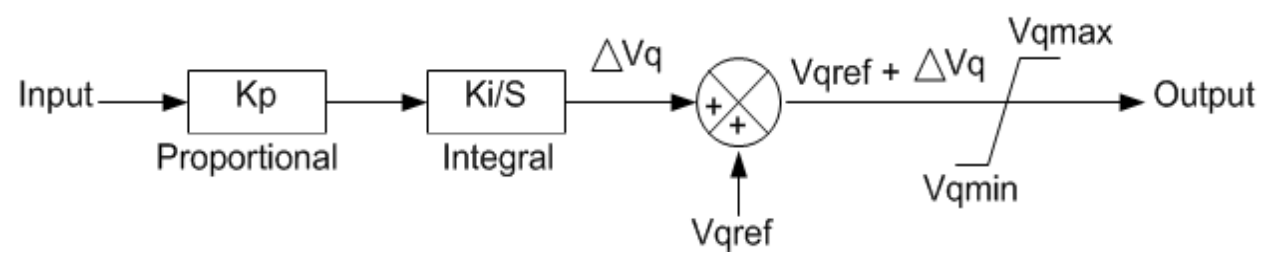

Figure 2. SSSC PI controller block diagram

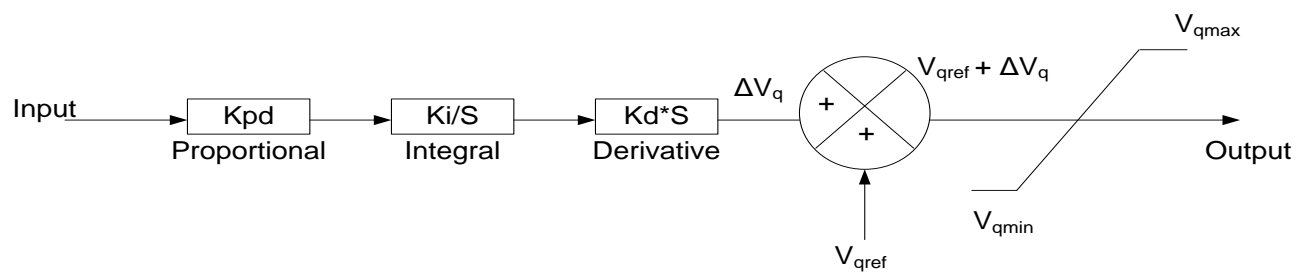

Figure 3. SSSC PID controller block diagram

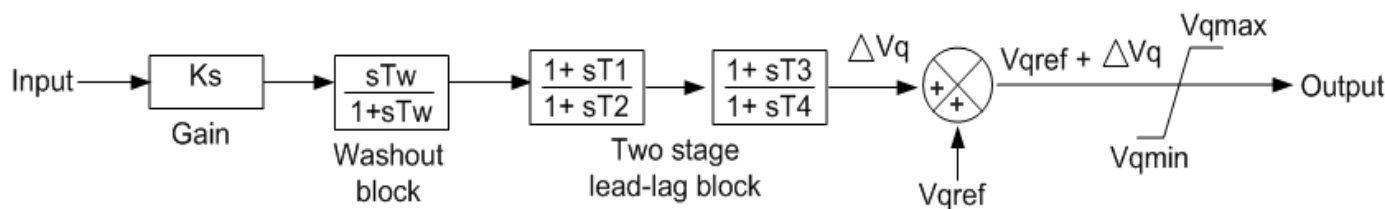

Figure 4. SSSC Generic controller block diagram

\section{RESEARCH METHOD}

\subsection{Multi-machine model}

The multi-machine model consists of two power generation substations and one load centre (dynamic load) at bus 4 as shown in Figure 5. The power generation G1 and G2 were set as 2100 MVA and 1400 MVA, respectively while the dynamic load as a major load was set as 2200MW. G1 is connected with L1 with $280 \mathrm{~km}$ and L2 is divided by two sides of $150 \mathrm{~km}$ to create a single-phase fault at the midpoint of the line. The generation G2 is connected with L3 of $50 \mathrm{~km}$. After that, to improve the stability, the SSSC device will be located at bus B2 in series with L1 with three types of controllers i.e. PI, PID and Generic controllers [21] as shown in Figure 6.

\subsection{Multi-machine transient stability}

Firstly, design the circuit diagram by using MATLAB Simulink based on a single line diagram [16] which consists of power generation as a power source, transmission line, load and bus. After that, set all the parameters of the components that have been used to avoid errors. Choosing suitable parameter settings is important as the SSSC device is a phasor type. Then, run the simulation before and during the fault. If there is a fault, the system will become unstable between each phase. Therefore, the SSSC device will be

Multi-machine transient stability by using static synchronous series compensator (Nur Ashida Salim) 
implemented to improve the system by using three types of controllers. Finally, record the time taken for the system to stabilise and compare between the three types of controllers. The overall procedure is shown in Figure 7.

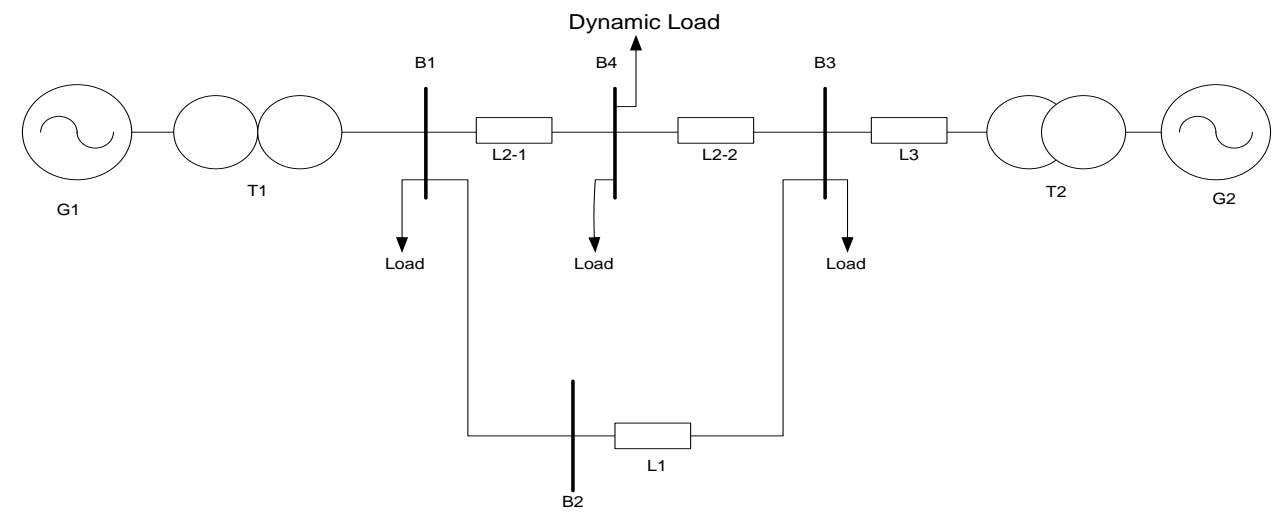

Figure 5. Single line diagram of multi-machine power system without SSSC device

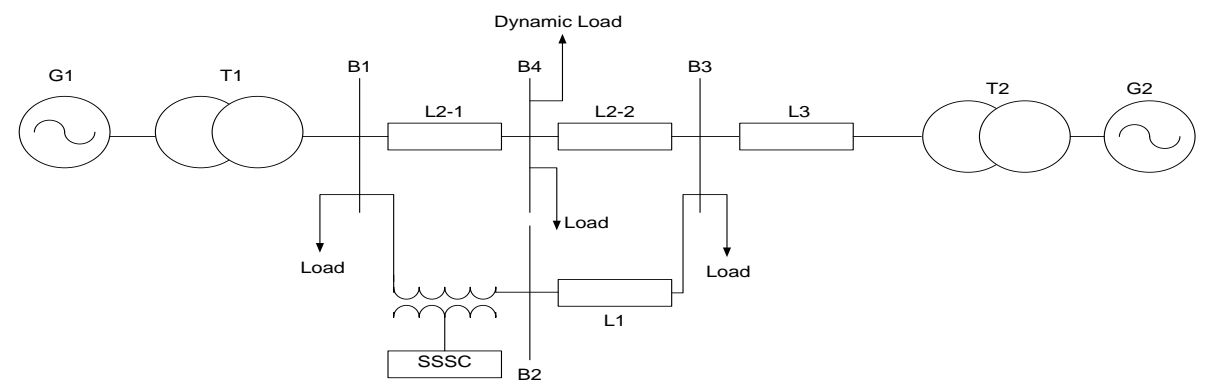

Figure 6. Single line diagram of multi-machine power system with SSSC device

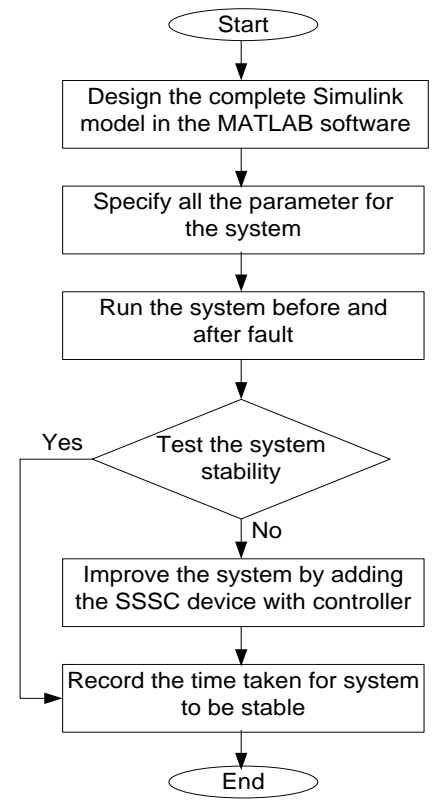

Figure 7. Flowchart of a complete multi-machine transient stability system 


\subsection{Multi-machine system without SSSC}

Figure 8 illustrates the Simulink model without any disturbance occurring in the system. The power generation block that acts as the power source was taken from Mathwork [23].

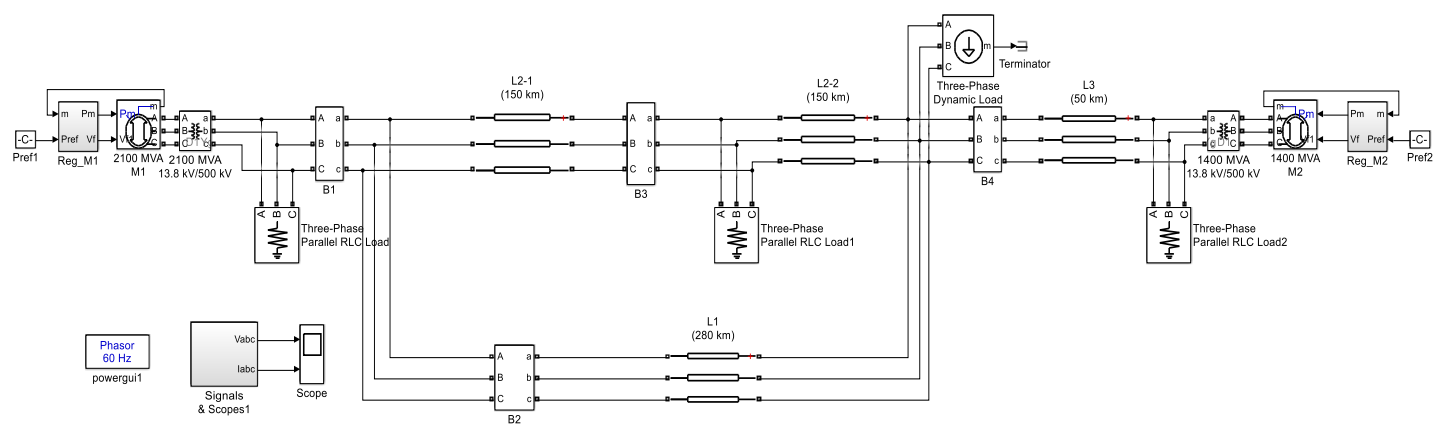

Figure 8. Simulink model of multi-machine power system without SSSC device

The waveform shown in Figure 9 shows that the system voltage is stable since each of the phases is synchronous with each other. Therefore, the FACTS device is not required during this condition.

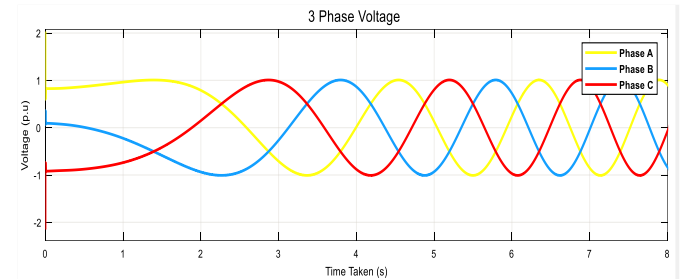

Figure 9. Voltage waveform of multi-machine power system without fault

\section{RESULTS AND ANALYSIS}

System stability was tested when a single phase fault occurred in the middle of the transmission line between L2-1 and L2-2 and setting time to fault occurrence is at the early stage of initial system stabilisation.

\subsection{Case 1: Fault at the Beginning of System}

Figure 10 shows the model of a multi-machine system used in this research. The single phase fault is initiated at L2-2. The analysis of the stability will be explained in the following sub-section.

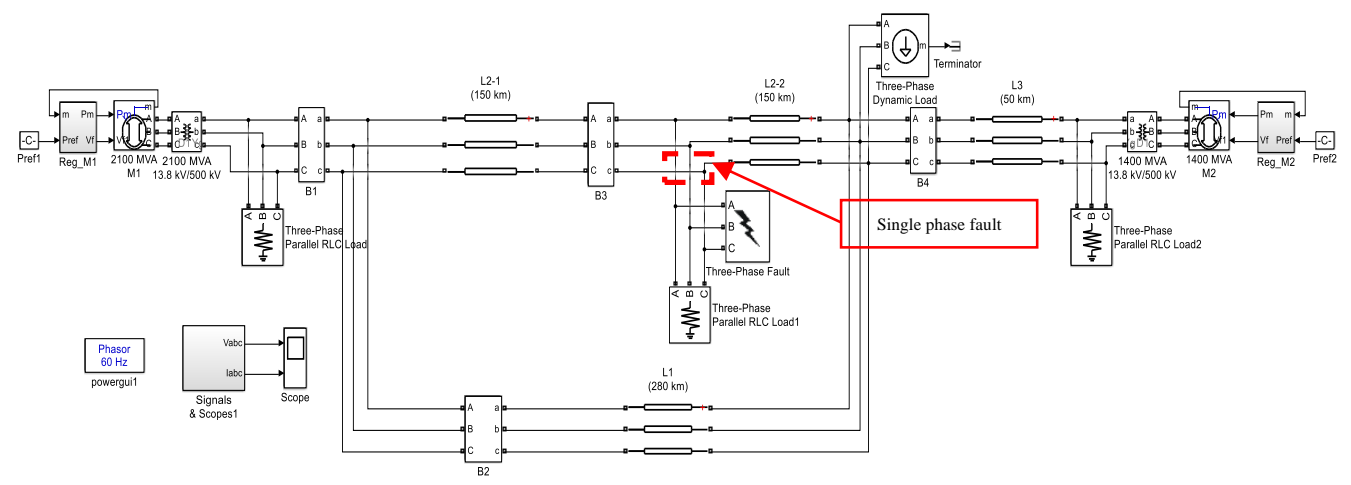

Figure 10. Model of a multi-machine system used in this research 


\subsubsection{Single phase fault of multi-machine model without SSSC device}

During the occurrence of a single-phase fault, the fault affected the system at $0.2 \mathrm{~s}$ and the circuit breaker opened at $0.3 \mathrm{~s}$ at an early stage of fault as shown in Figure 11. After clearing the fault, Phase A reached 1 p.u at $0.708 \mathrm{~s}$.

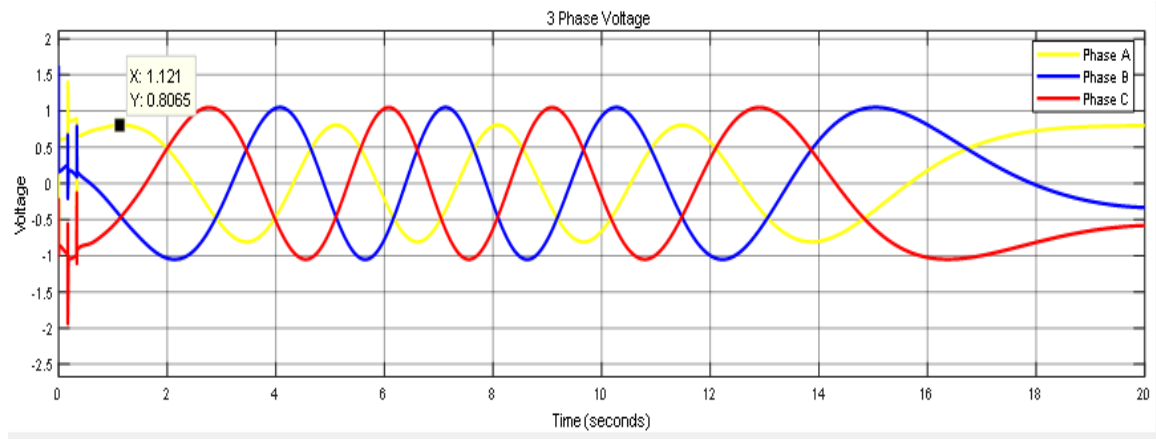

Figure 11. Voltage waveform of single phase fault of multi-machine power system without SSSC

\subsubsection{Single phase fault of multi-machine model with SSSC device}

An SSSC device is proposed in this research, therefore the system is improved by installing the SSSC device that is connected in series with the transmission line. The SSSC block diagram can be obtained from the Simulink library and set as a phasor type with a frequency of $60 \mathrm{~Hz}$. The model is shown in Figure 12. At the beginning of the test, the SSSC device is tested without using any additional controller. As a result, Phase A took $0.6962 \mathrm{~s}$ to reach 1p.u which is $0.012 \mathrm{~s}$ faster than without using SSSC. This is shown in Figure 13.

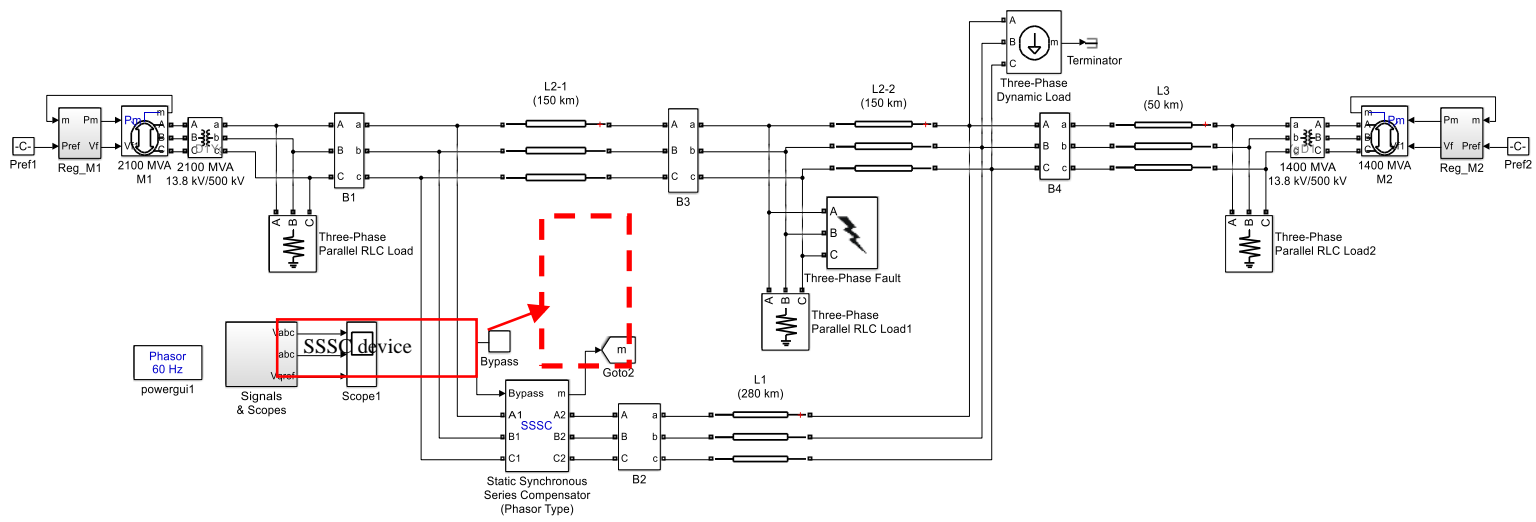

Figure 12. Simulink model of single phase fault of multi-machine power system with SSSC

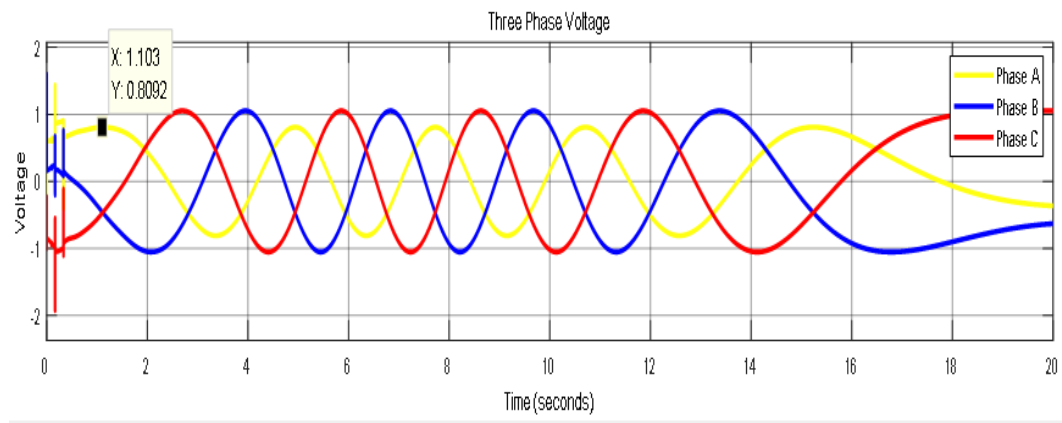

Figure 13. Voltage waveform of single phase fault of multi-machine power system with SSSC 


\subsubsection{Single phase fault of multi-machine model with SSSC PI controller}

A Proportional Integral (PI) controller is shown in Figure 14 which consists of proportional and integration gain blocks [24]. The input of the controller uses angular speed deviation, dw from both machines.

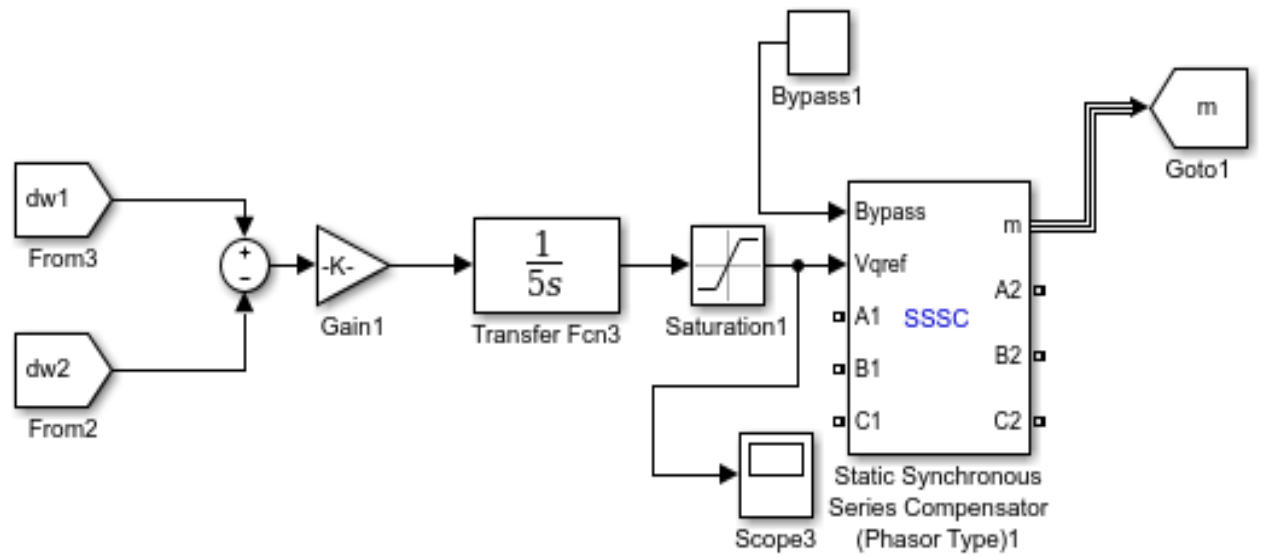

Figure 14. SSSC with PI controller

After installing the SSSC with a PI controller, the system became stable at $0.814 \mathrm{~s}$ and each phase oscillated at the same value of voltage at 1 p.u as shown in Figure 15. Since the PI controller used angular speed deviation $\mathrm{dw}$ as an input to the Vqref, therefore the damping of Vqref stabilised at $8 \mathrm{~s}$ as shown in Figure 16.

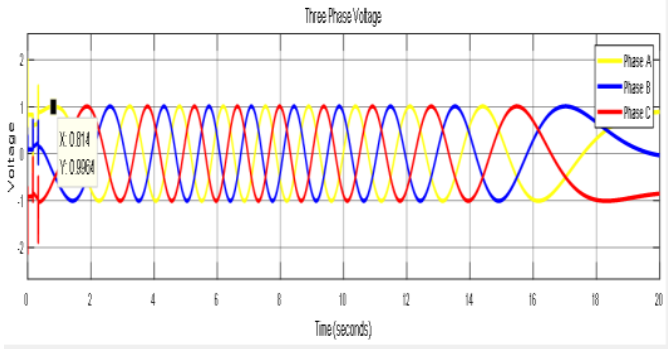

Figure 15. Voltage waveform of single phase fault of multi-machine power system with SSSC PI controller

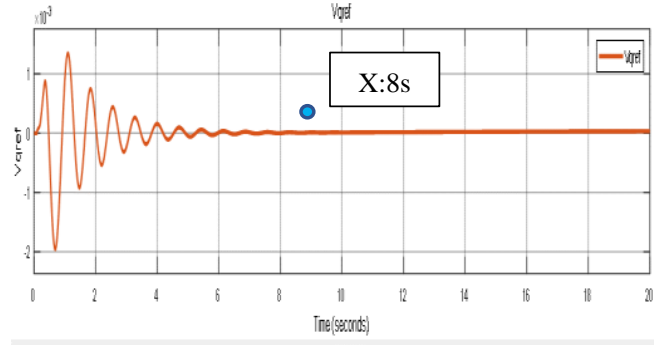

Figure 16. Vqref waveform of single phase fault of multi-machine power system with SSSC PI controller

\subsubsection{Single phase fault of multi-machine model with SSSC PID controller}

The Proportional Integral Derivation (PID) controller contains proportional, integral and derivative gain blocks [25]. The PID controller also uses angular speed deviation, dw as an input to the system as shown in Figure 17. 


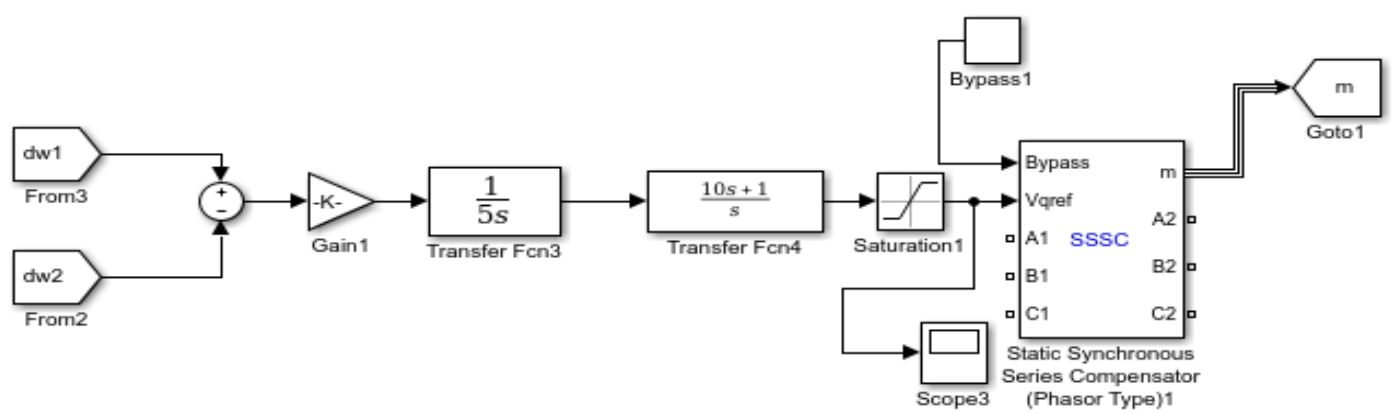

Figure 17. SSSC with PID controller

After the single-phase fault was cleared, the system became stable and synchronous with each other at $0.776 \mathrm{~s}$ as shown in Figure 18 and the damping of Vqref stabilised at $6 \mathrm{~s}$ which is much faster than the PI controller and is shown in Figure 19.

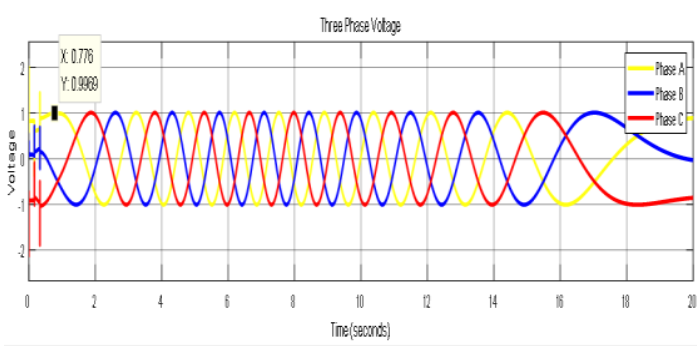

Figure 18. Voltage waveform of single phase fault of multi-machine power system with SSSC PID controller.

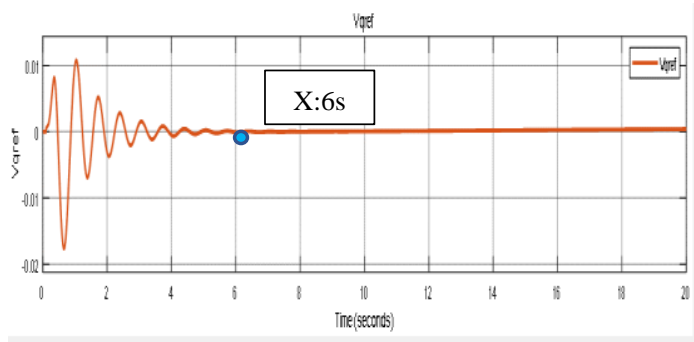

Figure 19. Vqref waveform of single phase fault of multi-machine power system with SSSC PID controller

\subsubsection{Single phase fault of multi-machine model with SSSC Generic controller}

Figure 20 shows the block diagram of the generic controller. Based on the block diagram, the input is the same as the PI and PID controllers which use angular speed deviation, $\mathrm{dw}$ as an input parameter. The block diagram consists of a washout that has a constant value (1-20 s) in order to pass the high oscillation signal to the next block and a two stage lead-lag block is used to adjust the phase lag between the outgoing and ingoing signals [13]. Here the value of parameters, $\mathrm{Tw}=10, \mathrm{~T} 2=\mathrm{T} 4=0.3$ are set as a constant and gain, $\mathrm{T} 1$ and $\mathrm{T} 3$ are selected by the trial and error method. For this paper, the suitable values were gain $=65.49, \mathrm{~T} 1$ $=0.5527$ and $\mathrm{T} 3=0.2563[20]$.

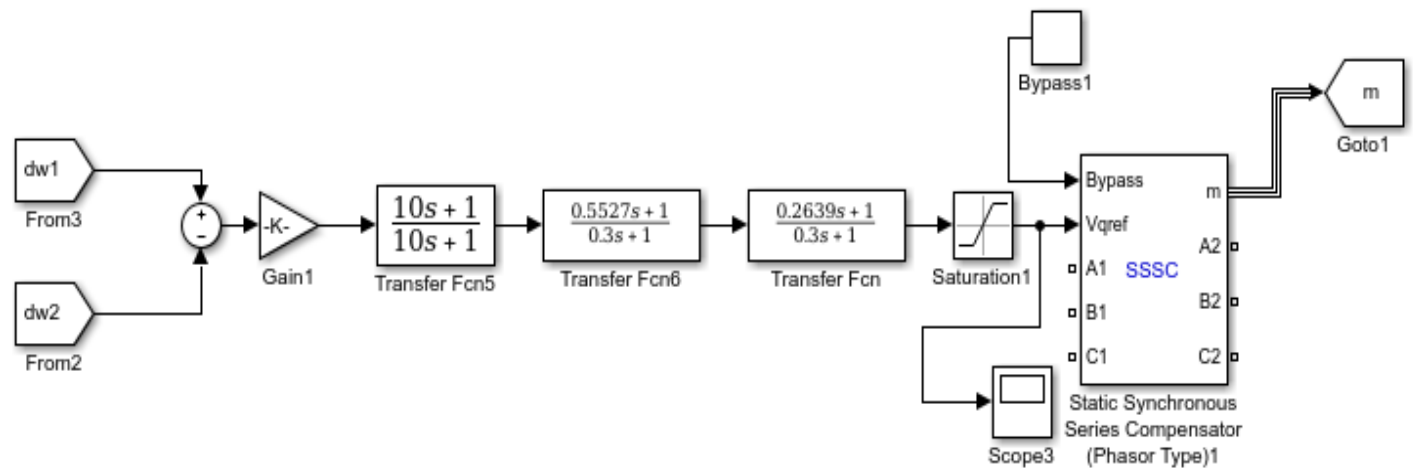

Figure 20. SSSC generic controller 
As a result, Figure 21 shows the system becoming stable at $0.7737 \mathrm{~s}$ and each phase oscillating in the same value of voltage which is $1 \mathrm{p}$.u. Since the angular speed deviation dw was also used as an input to the Vqref, the damping of Vqref was stable at $2 \mathrm{~s}$ as shown in Fig 22.

The performance result of the system stability test has been recorded and summarised as in Table 1 . Firstly, the stability system was tested for with and without the SSSC device. As a FACTS device is capable of improving voltage stability and transient stability, one FACTS member, the SSSC device was installed in order to improve the stability and prevent unstable condition. Therefore, SSSC is connected in series with the transmission line and set as a phasor type. Since the purpose of an SSSC device is to improve transient stability, the value of Phase A increased to 0.83 p.u but did not reach 1 p.u like the other phases. As a result, the system is said to be unstable without using any additional SSSC controller.

Since the system was still not stable even though SSSC was installed, three types of controllers were added to the system i.e. proportional integral (PI), proportional integral derivative (PID) and Generic controllers. All three controllers used angular speed deviation, DW as an input and were injected to Vqref. From Table 1, all controllers have improved the system by oscillating all the phases at the same value after clearing the fault. The difference between voltage stability doesn't make any difference but for Vqref, the Generic controller only took $2 \mathrm{~s}$ to stabilise and was the fastest among the three controllers. As a result, the SSSC device needs an additional controller to improve the power system stability.

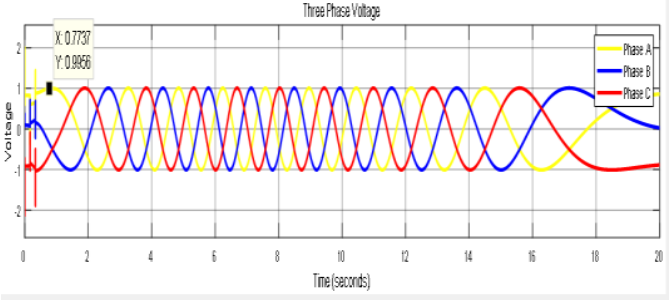

Figure 21. Voltage waveform of single phase fault of multi-machine power system with SSSC Generic controller.

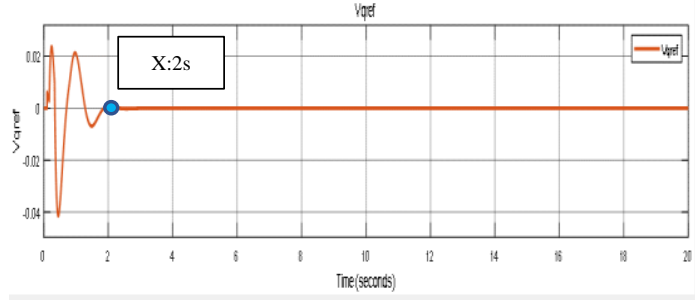

Figure 22. Vqref waveform of single phase fault of multi-machine power system with SSSC Generic controller.

Table 1. Comparison of SSSC with and without controller

\begin{tabular}{|c|c|c|c|}
\hline \multirow[t]{2}{*}{ Type Controller } & \multirow{2}{*}{$\begin{array}{l}\text { Voltage } \\
\text { Phase A }\end{array}$} & \multicolumn{2}{|c|}{ Stability Time (s) } \\
\hline & & Voltage & Vqref \\
\hline Without SSSC & 0.8 p.u & - & - \\
\hline Without Controller & 0.83 p.u & - & - \\
\hline PI & 1 p.u & $0.81 \mathrm{~s}$ & $8 s$ \\
\hline PID & 1 p.u & $0.77 \mathrm{~s}$ & $6 s$ \\
\hline Generic & 1 p.u & $0.77 \mathrm{~s}$ & $2 s$ \\
\hline
\end{tabular}

\section{CONCLUSION}

The study of the multi machine transient stability has been proven by using Matlab Simulink. The operation of the multi machine transient stability required two power generation with a huge power value to supply to the dynamic load as a major load. The system operation will run smoothly if no disturbance occurs. This research was able to observe the multi machine stability when subjected to a single phase fault. The SSSC device has proven its ability to improve the power system stability in the system. However, SSSC cannot operate by itself without using any additional controller. Three types of controllers have been modelled to control the SSSC device. They are the Proportional Integral (PI), Proportional Integral Derivative (PID), and Generic controllers. As a conclusion, SSSC with Generic controller is very suitable because of its shorter stability time and less damping as the Generic controller is suitable to use with any FACTS device.

\section{ACKNOWLEDGEMENT}

The authors would like to thank the Research Management Institute (RMI), Universiti Teknologi MARA, Malaysia and the Ministry of Higher Education (MOHE), Malaysia through research grant 600IRMI/DANA 5/3/BESTARI (121/2018) for the financial support towards this research. 


\section{REFERENCES}

[1] P. Kundur, J. Paserba, and S. Vitet, "Overview on definition and classification of power system stability," in CIGRE/IEEE PES International Symposium Quality and Security of Electric Power Delivery Systems, CIGRE/PES 2003, pp. 1-4, 2003.

[2] M. A. A. T. Aaron Don M. Africa, Patrick Bernard T. Arevalo, Arsenic S. Publico, "Linear System Interconnections, Steady-State Analysis and Stability Theory," Int. J. Adv. Trends Comput. Sci. Eng., vol. 8, no. 4, pp. 1395-1398, 2019.

[3] N. A. Salim, M. M. Othman, I. Musirin, M. S. Serwan, and S. Busan, "Risk assessment of dynamic system cascading collapse for determining the sensitive transmission lines and severity of total loading conditions," Reliab. Eng. Syst. Saf., vol. 157, pp. 113-128, 2017.

[4] D. Casagrande, A. Astolfi, R. Ortega, and D. Langarica, "A solution to the problem of transient stability of multimachine power systems," in 2012 IEEE 51st Annual Conference on Decision and Control (CDC), pp. 1703-1708, 2012.

[5] P. Kundur et al., "Definition and Classification of Power System Stability IEEE/CIGRE Joint Task Force on Stability Terms and Definitions," IEEE Trans. Power Syst., vol. 19, no. 3, pp. 1387-1401, 2004.

[6] Z. Wang and M. Lemmon, "Voltage and Frequency Stability of Weak Power Distribution Networks with DroopControlled Rotational and Electronic Distributed Generators," Thesis, pp. 1-32.

[7] L. V. Abha Tripathi, K. Uma Rao, "Multi-Machine Stability Using Dynamic Inversion Technique," Int. J. Electr. Comput. Eng. (IJEC), vol. 7, no. 6, pp. 3176-3189, 2017.

[8] E. Ghahremani and I. Kamwa, "Optimal placement of multiple-type FACTS devices to maximize power system loadability using a generic graphical user interface," IEEE Trans. Power Syst., vol. 28, No. 2, pp. 764-778, 2013.

[9] B. Sehgal, S. P. Bihari, Y. Kumari, R.N.Chaubey, and Anmol Gupta, "Performance of FACTS Devices for Power System Stability," Indones. J. Electr. Eng. Informatics, vol. 3, no. 3, p. 135-140, 2015.

[10] S. Do Nascimento and M. M. Gouvêa, "Voltage Stability Enhancement in Power Systems with Automatic Facts Device Allocation," in Energy Procedia, vol. 107, pp. 60-67, 2017.

[11] M. Hasan, "Application of power electronics in power systems," in Handbook of Research on Power and Energy System Optimization, 2018.

[12] M. Alizadeh, S. Ganjefar, and M. Farahani, "Intelligent PID controller design of SSSC for power system stability enhancement," Proc. - 2011 2nd Int. Conf. Control. Instrum. Autom. ICCIA 2011, pp. 7-12, 2011.

[13] A. Patel, P. Raval, and D. Patel, "Application of SSSC-Damping Controller for Power System Stability Enhancement," in 2017 International Conference on Research and Innovations in Science, Engineering \& Technology, pp. 123-133, 2017.

[14] A. P. Vaidya and R. V Patil, "Comparison of different types of transient stability assessments during congestion," in 2012 International Conference on Advances in Engineering, Science and Management (ICAESM), pp. 232-237, 2012.

[15] D. A. Ingole and P. V. N. Gohokar, "Voltage Stability Improvement In Multi-bus System Using Static Synchronous Series Compensator," Energy Procedia, vol. 117, pp. 999-1006, 2017.

[16] N. Voraphonpiput and T. Bunyagul, "Power Flow Control with Static Synchronous Series Compensator (SSSC)," International Energy Journal, vol. 9, pp. 117-128, 2008.

[17] Bhalani Kamal Kumar, Assi Prof. Piyush Dodiya, "Improvement of Power system transient stability using static synchronous series compensator (SSSC)," International Journal of Science Technology and Engineering, vol. 3, no. 1, pp. 170-176, 2016.

[18] P. Dhoble and A. Bhandakkar, "Active Reactive Power Flow Control Using Static Synchronous Series Compensator (SSSC)," IOSR Journal of Electrical and Electronics Engineering (IOSR-JEEE), vol. 7, no. 6, pp. 59-71, 2013.

[19] Jalla Pavan Sai Kumar Reddy, Prasad Janga, "Power Flow Improvement in Transmission Line Using Upfc," International Journal of Electronics \& Communication Technology, vol. 7, no. 4, pp. 9-12, 2016.

[20] Habibur, Md. Fayzur Rahman, Harun, "Modelling \& Performance Comparison Of Different Types Of SSSC-Based Controllers,", International Journal Of Engineering Research \& Technology, vol. 1, no. 7, pp. 1-6, 2012.

[21] A. D. Falehi, M. Rostami, A. Doroudi, and A. Ashrafian, "Optimization and coordination of SVC-based supplementary controllers and PSSs to improve power system stability using a genetic algorithm," Turkish J. Electr. Eng. Comput. Sci., vol. 20, no. 5, pp. 639-654, 2012.

[22] S. Panda, S. C. Swain, P. K. Rautray, R. K. Malik, and G. Panda, "Simulation Modelling Practice and Theory Design and analysis of SSSC-based supplementary damping controller," Simul. Model. Pract. Theory, vol. 18, no. 9, pp. 1199-1213, 2010.

[23] J. Jeffers and J. Reinders, "Math Library," Intel Xeon Phi Coprocessor High Perform. Program, pp. 325-342, 2013.

[24] K. L. \& M. K. Rihem Farkh, "Stabilizing Sets of PI/PID Controllers for Unstable Second Order Delay System," Int. J. Autom. Comput., vol. 11, pp. 210-222, 2014.

[25] Alizadeh, Mojtaba Ganjefar, Soheil Farahani, Mohsen, "Intelligent PID controller design of SSSC for power system stability enhancement," Proceedings - 2011 2nd International Conference on Control, Instrumentation and Automation, ICCIA 2011, pp. 7-12, 2011. 